\title{
Modified halloysite nanotubes reduce the toxic effects of zearalenone in gestating sows on growth and muscle development of their offsprings
}

Rui Gao ${ }^{\dagger}$, Qingwei Meng ${ }^{\dagger}$, Jianan Li, Min Liu, Yuanyuan Zhang, Chongpeng Bi and Anshan Shan ${ }^{*}$

\begin{abstract}
Background: Zearalenone (ZEN) is an estrogenic mycotoxin that is primarily produced by Fusarium fungi and has been proven to affect the reproductive capacity of many species to varying degrees. The present experiment was designed to study the maternal persistent effects of zearalenone toxicity in gestating sows on growth and muscle development of their offsprings, and the alleviation of zearalenone toxicity by modified halloysite nanotubes (MHNTs).

Methods: Eighteen sows were fed with one of three dietary treatments that included the following: (1) a control diet, (2) a contaminated grain diet (with $50 \%$ moldy corn, $2.77 \mathrm{mg} / \mathrm{kg}$ ZEN), and (3) a contaminated grain diet (with $50 \%$ moldy corn, $2.76 \mathrm{mg} / \mathrm{kg}$ ZEN) $+1 \%$ MHNTs. Each sow was exclusively fed its experimental diets from 35 to $70 \mathrm{~d}$ of gestation at a total of $2 \mathrm{~kg}$ daily. Muscle samples were collected from six piglets per treatment at birth, weaning and finishing.

Results: The results showed that feeding the sows with the ZEN-contaminated diets from 35 to $70 \mathrm{~d}$ of gestation decreased the ADG, ADFI and G:F of their offsprings $(P<0.05)$. The muscle fiber numbers in the newborn, weaning and growing-finishing pigs and the muscle fiber diameters at birth and weaning were also decreased by maternal ZEN exposure $(P<0.05)$. The expressions of IGF-I, IGF-II, Myf-5 and Msth at birth and IGF-II, Pax7, Myf-5 and MyoD1 at weaning were altered by feeding gestating sows with ZEN-contaminated diets $(P<0.05)$. The MHNTs reduced most of the ZEN-induced toxic effects: the ADG and ADFI on growth performance, the muscle fiber numbers at weaning and finishing and the muscle fiber diameters at weaning $(P<0.05)$. The expression levels of /GF-I/ and Msth in newborn piglets and IGF-II and Myf-5 in weaning piglets were also prevented by adding $1 \%$ MHNTs $(P<0.05)$.

Conclusions: The present study demonstrated that the offsprings of sows fed with ZEN-contaminated diets from 35 to 70 day of gestation exhibited weakening on growth performance, physiological changes in their muscle fibers and alterations of mRNA expression in their muscle tissues, and also indicated that MHNTs prevented most of the ZENinduced weakening in the muscle tissues.
\end{abstract}

Keywords: Growth, MHNTs, Muscle development, Offsprings, Sows, Zearalenone

\footnotetext{
* Correspondence: asshan@neau.edu.cn

Rui Gao and Qingwei Meng are co-first authors

${ }^{\dagger}$ Equal contributors

Institute of Animal Nutrition, Northeast Agricultural University, Harbin 150030,

P. R. China
}

Biomed Central (c) 2016 Gao et al. Open Access This article is distributed under the terms of the Creative Commons Attribution 4.0 International License (http://creativecommons.org/licenses/by/4.0/), which permits unrestricted use, distribution, and reproduction in any medium, provided you give appropriate credit to the original author(s) and the source, provide a link to the Creative Commons license, and indicate if changes were made. The Creative Commons Public Domain Dedication waiver (http://creativecommons.org/publicdomain/zero/1.0/) applies to the data made available in this article, unless otherwise stated. 


\section{Background}

Fusarium graminearum is most frequently isolated from maize in temperate climates, and zearalenone production often occurs during the cold weather storage of highmoisture feeds carrying the mold [1]. Zearalenone (ZEN) is a mycotoxin that is produced primarily by fungi of the genus Fusarium in foods and feeds. ZEN has frequently been implicated in reproductive disorders in farm animals and occasionally in hyperoestrogenic syndromes in humans [2]. In farm animals, swine seem to be particularly sensitive to mycotoxins [3]. Meanwhile, maternal effects which play an important role on offspring's growth and muscle development were proved by many previous researchers [4]. ZEN-related problems frequently occur in piglets under natural conditions and are by exposure in the uterus, the placental transfer from an exposed sow to her piglets and by ZEN stored in the sow during gestation and released via the suckling of the piglets [5].

There has been an increased interest in the application of halloysite nanotubes (HNTs) in order to find a way to detoxify contaminated feedstuffs or diets which is appropriate for large quantities of raw material sources, inexpensive, simple and results in products of stable quality. Halloysite is a type of aluminosilicate clay with a hollow nano-tubular structure and a set of characteristics that make it cheap, abundantly available, durable, highly mechanically strong and biocompatible [6]. Around the world, halloysite nanotubes have been used as nanocomposites, nanocontainers [7] and new drug carriers in medicine $[8,9]$, but the use of HNTs in animals as adsorbents has not yet been reported.

Indeed, many studies of laboratory animals, farm animals and humans have reported that exposure to the estrogenic effects of ZEN causes relevant reproductive performance alterations $[10,11]$. It has been reported that maternal zearalenone exposure causes fetal malformations and physiological alterations to sexual organs [12, 13]. However, few studies have examined the effects of zearalenone on growth or muscle development, particularly in combination with maternal effects. These factors prompted us to begin a more extensive investigation of the possible effects of maternal zearalenone exposure on offspring growth and muscle development and to exploit a new adsorbent to mitigate the negative effects of zearalenone contamination.

\section{Methods}

\section{Mold strain}

Fusarium graminearum has previously been shown to produce ZEN in corn [14]. The fungus used in this experiment was purchased from the Agricultural Culture Collection of China (No. ACCC36249) and cultivated on potato dextrose agar (PDA, potato extract $0.4 \%$, glucose $2 \%$ and agar $1.5 \%$, pH $5.6 \pm 0.2$ ). The experimental culture media were obtained from Fluka (Bornem, Belgium) [15].

The corn used in this experiment was obtained from Xiang Fang Experimental Bases (Northeast Agricultural University, China) and milled in a hammer mill with a 40mesh screen (Trapp-TRF model 90). The in vitro ZEN production was conducted according to the procedures outlined by Ligia Martins [14]. The studies of mycotoxin production by Fusarium graminearum were performed in duplicate on trays containing 1,000 g of sterilized cracked corn following the addition of $400 \mathrm{~mL}$ of distilled water and adjusting the aw to 0.98 by water activity meter (HD4, HuaKe Instrument \& Meter Co. Ltd., Wuxi, China).

The corn contained no fungal infection or ZEN contamination. Autoclaved substrate was inoculated with $40 \mathrm{~mL}$ of the spore suspension according to the following procedure: $100 \mathrm{~mL}$ of sterile distilled water were added to each slant of the 5-day-old culture, and the surface of the agar was gently scraped to produce a turbid suspension with $1 \times 10^{14}$ spores $/ \mathrm{mL}$. One hundred milliliters of this suspension were added to the cracked corn. The inoculated flasks were stirred daily for the first $5 \mathrm{~d}$. The culture conditions used in this experiment, $28{ }^{\circ} \mathrm{C}$ for $15 \mathrm{~d}$ followed by $12{ }^{\circ} \mathrm{C}$ with ZEN peaking on the 35th day of incubation, reflected the earlier work reported by Ligia Martins [14]. To equalize the moisture contents of the samples, each sample was dried at $60{ }^{\circ} \mathrm{C}$ for $96 \mathrm{~h}$ and stored in a freezer at $-20^{\circ} \mathrm{C}$ until analysis [16].

\section{Modification of the adsorbent}

The adsorbent used in experiment was that described by Zhang et al. [17]. Halloysite nanotube powder (HNTs), was purchased and refined from Golden Sunshine Ceramics Co., Ltd. (Zhengzhou, China). The molecular formula of halloysite nanotube was $\mathrm{Al}_{2} \mathrm{Si}_{2} \mathrm{O}_{5}(\mathrm{OH})_{4} \cdot \mathrm{nH}_{2} \mathrm{O}$, composed of $95 \%$ kaolinite, trace amounts of quartz and natroalunite. The crystal diameter was 10 to $50 \mathrm{~nm}$ and the crystal length was less than $1 \mu \mathrm{m}$. The proportion of granule $(<2 \mu \mathrm{m})$ was $70 \%$ in the original mineral.

The previously reported method of Jinhua was used to prepare the powder [7]. All solutions were prepared using distilled water. The powder was prepared as follows: A water suspension solution (5\% in mass) was prepared by adding water to dry halloysite mineral. The suspension solution was intensively stirred for $2 \mathrm{~h}$ and sprayed to dry at $200{ }^{\circ} \mathrm{C}$ to obtain fine powder. Before use, dry halloysite powder was sieved to eliminate aggregates.

Modification of the halloysite nanotubes was accomplished using stearyldimethylbenzylammonium chloride (SKC) as a surfactant (Jingwei Chemical Co., Ltd., Shanghai, China) according the previously described methods of Lemke [18]. HNT (100 g) were treated with $1,000 \mathrm{~mL}$ distilled water containing SKC (0.5 \%) and 
mixed at a speed of 2,300 $\mathrm{g}$ with a reaction time of $10 \mathrm{~min}$ at $50{ }^{\circ} \mathrm{C}$. When the reaction was complete, the suspensions were filtered, washed three times with deionised water, dried at $80{ }^{\circ} \mathrm{C}$ and crush $100 \mathrm{~g}$ of HNT to obtain particles that were less than $45 \mu \mathrm{m}$ in a beater mill at 7,400 $\mathrm{g}$ for $3 \mathrm{~min}$. The made-up particles were added in the contaminated diets evenly to make the MHNTs diets.

Figure 1 shows the images after electric microscope (EM). It can be seen that the samples consisted of cylindrical tubes. After treatment with SKC, the dispersion of the halloysite (Fig. 1b) was increased compared to the untreated HNT powder (Fig. 1a). Moreover, the lumen of modified nanotubes shown in Fig. 1d was enlarged compared with untreated nanotubes (Fig. 1c). As shown in Fig. 1c and d, the external surface of the treated HNT was cruder than the natural halloysite [17].

\section{Animals and experimental design}

Eighteen pregnant Yorkshire sows were randomly divided into the following three treatment groups ( 6 per treatment): (1) control, (2) contaminated grains (with $50 \%$ moldy corn); and (3) contaminated grains (with $50 \%$ moldy corn) $+1 \%$ modified HNTs (MHNTs). The doses of the MHNTs were selected based on the research of Jiang $[19,20]$. The pregnant sows were housed in individual stalls after $35 \mathrm{~d}$ of gestation (GDs). Each sow was fed exclusively with the appropriate experimental diet from $d$ 35 to $\mathrm{d} 70$ of gestation at a total of $2 \mathrm{~kg}$ daily. All of the feedstuffs were subjected to post-processing analytical control. The feed compositions were compared using validated analytical methods (National Standards of the People's Republic of China, GB/T 19540-2004). ZEN was the major contaminant and was present at $0.03 \mathrm{mg} / \mathrm{kg}$ in the control diet, $2.77 \mathrm{mg} / \mathrm{kg}$ in the contaminated diet, $2.76 \mathrm{mg} / \mathrm{kg}$ in the adding adsorbent contaminated diet. The concentration of deoxynivalenol (DON) which was also produced by Fusarium graminearum was $0.04 \mathrm{mg} / \mathrm{kg}$ in the contaminated diet, lower than the limits of national standards $(1 \mathrm{mg} / \mathrm{kg})$. Analyses of the corn and diets with GC-MS were performed to provide detailed characterizations of the trichothecene mycotoxin patterns and revealed that the B-trichothecene mycotoxins, such as 15-acetyldeoxynivalenol, 3-acetyldeoxynivalenol, and nivalenol, and A-trichothecene mycotoxin HT-2 toxins were lower than the detection limits [21]. At $7 \mathrm{~d}$ of age all piglets, the piglets received an iron injection, and the males were castrated. The piglets were weaned at $21 \mathrm{~d}$ of age and moved to post-weaning rooms with an ambient temperature of $27{ }^{\circ} \mathrm{C}$. After weaning, the piglets had ad libitum access to the standard diets and water intake until finishing in individual pens. All experimental diets (Table 1) were formulated to meet or exceed the National Research Council nutrient requirements (2012) [22].
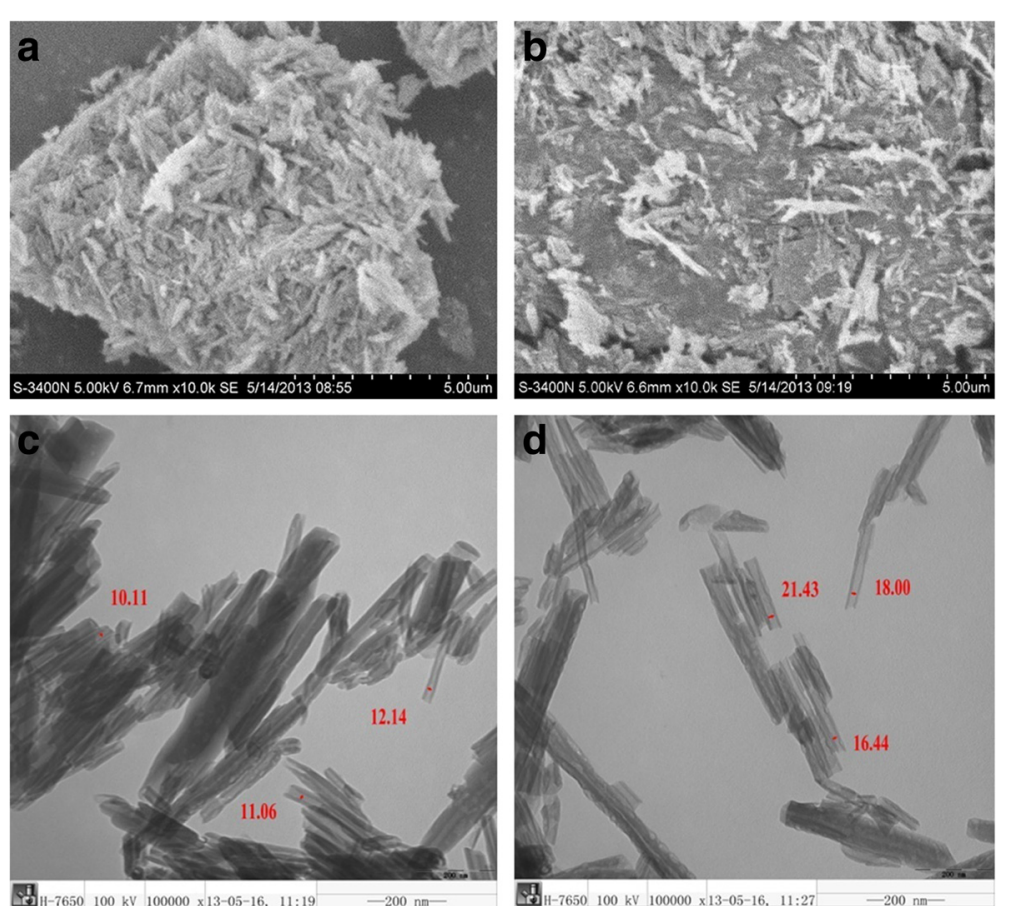

Fig. 1 a Scanning electron microscope (EM) image of the halloysite nanotubes (HNT) powder. b Scanning EM image of modified HNT (MHNTs) powder with increased dispersity. c Transmission EM images of the HNT. d Transmission EM image of modified HNT with enlarged internal diameters [17] 
Table 1 Percentage composition of the diet

\begin{tabular}{|c|c|c|c|c|}
\hline Parameters & Control $^{c}$ & Contaminated grains $^{c}$ & Contaminated grains $+1 \% \mathrm{MHNTs}^{\mathrm{c}}$ & Lactation \\
\hline \multicolumn{5}{|l|}{ Ingredient, \% } \\
\hline Control corn & 62.40 & 31.20 & 31.20 & 63.80 \\
\hline Contaminated corn & - & 31.20 & 31.20 & - \\
\hline Soybean meal & 16.00 & 16.00 & 16.00 & 20.00 \\
\hline Wheat bran & 18.00 & 18.00 & 17.00 & - \\
\hline MHNTs & - & - & 1.00 & - \\
\hline Full-fat soybean & - & - & - & 12 \\
\hline Limestone & 1.00 & 1.00 & 1.00 & 0.93 \\
\hline Dicalcium phosphate & 1.10 & 1.10 & 1.10 & 1.77 \\
\hline Salt & 0.50 & 0.50 & 0.50 & 0.50 \\
\hline Vitamin and mineral premix ${ }^{a}$ & 1.00 & 1.00 & 1.00 & 1.00 \\
\hline \multicolumn{5}{|l|}{ Analyzed composition } \\
\hline Metabolizable energy, MJ/kg & 11.90 & 11.84 & 11.75 & 12.90 \\
\hline Crude protein & 14.51 & 14.45 & 14.31 & 18.48 \\
\hline Calcium & 0.69 & 0.68 & 0.67 & 0.79 \\
\hline Total phosphorus & 0.61 & 0.61 & 0.60 & 0.64 \\
\hline Lysine & 0.65 & 0.67 & 0.66 & 0.98 \\
\hline Tryptophan & 0.16 & 0.16 & 0.16 & 0.23 \\
\hline Threonine & 0.52 & 0.52 & 0.52 & 0.69 \\
\hline Methionine + Cystine & 0.39 & 0.45 & 0.45 & 0.52 \\
\hline Concentration of ZEN', mg/kg & 0.03 & 2.77 & 2.76 & 0.01 \\
\hline
\end{tabular}

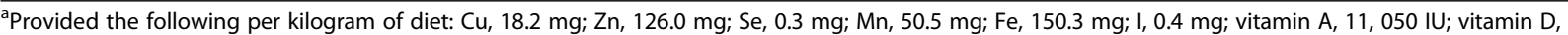
2,310 IU; vitamin E, $62.8 \mathrm{IU}$; vitamin K, $2.6 \mathrm{mg}$; riboflavin, $5.8 \mathrm{mg}$; pantothenic acid, $20 \mathrm{mg}$; niacin, $25 \mathrm{mg}$; vitamin B12, $326 \mu$ g; folate, $6.5 \mathrm{mg} ;$ pyridoxine, $1.8 \mathrm{mg}$; biotin, $350 \mu \mathrm{g}$; and thiamin, $1.9 \mathrm{mg}$

${ }^{b}$ Calculated values according to the Tables of Feed Composition and Nutritive Values in China [42] in this study

'Control: control diet; Contaminated grains: instead of $50 \%$ moldy corn; Contaminated grains: instead of $50 \%$ moldy corn + $1 \%$ MHNTs; ZEN Zearalenone, MHNTs modified Halloysite nanotubes

\section{Sample collection}

All of the animal experimental procedures were approved by the Ethical and Animal Welfare Committee of Heilongjiang Province, China.

Six piglets in each group were slaughtered via an intraarterial injection of pentobarbital $(200 \mathrm{mg} / \mathrm{kg})$ for general anesthesia at birth and six more at weaning. At the end of the experiment, 18 growing-finishing pigs from the three treatments were transported to the abattoir for slaughter. At birth, weaning and finishing, one pig was selected from each litter and slaughtered to collect samples.

After slaughter, longissimus muscle samples were quickly collected, frozen in liquid nitrogen, stored at $-80{ }^{\circ} \mathrm{C}$ and analyzed for gene expression by RNA extraction, followed by quantitative reverse transcription PCR [11]. Portions of the longissimus muscle samples were fixed in $4 \%$ paraformaldehyde in phosphate buffer $(0.12 \mathrm{~mol} / \mathrm{L}, \mathrm{pH}$ 7.4) for histochemical examination. The remaining organs were directly stored at $-20{ }^{\circ} \mathrm{C}$ for analysis.

\section{Growth performance}

The growth performance was evaluated from weaning to finishing. All the pigs were weighed individually at weaning and slaughter. The feed intakes per pen were recorded after weaning. The average daily gain (ADG), average daily feed intake (ADFI) and gain/feed (G:F) values were calculated.

\section{Histochemical examination}

The longissimus muscle samples were embedded in paraffin and cut into $10-\mu \mathrm{m}$ sections. The muscle sections were rehydrated via a series of incubations in xylene and ethanol solutions and then stained with hematoxylin and eosin for standard light microscopy. Ten fields were randomly selected to quantify the muscle fiber diameters. The majority of the muscle fibers were circular; thus, the diameters were easily measured. For the irregular muscle fibers, the maximum and minimum diameters of the muscle fiber circle were measured, and the average value of the maximum and minimum was regarded as the diameter of the fiber. The diameters of 10 muscle fiber per field were measured, and 100 muscle fibers per 
sample were quantified using the Motic Images Plus 2.0 software. The muscle fiber diameters were measured in a blinded fashion. The averaged data were used for calculations [4]. The percentages of muscle fibers were calculated based on the total fiber numbers per examined area, and this latter value for the control treatment was regarded as $100 \%$ [23].

\section{Quantitative real-time PCR}

Total RNA was extracted from the muscles $(30 \mathrm{mg}$ of tissue) of the piglets using the Trizol reagent (E.Z.N.A. ${ }^{\bullet}$ Total RNA Kit, Omega Bio-tek, Inc., United States). The RNA concentration was measured with a spectrophotometer at $260 / 280 \mathrm{~nm}$. The quality of the RNA was estimated by detecting the number of bands by agarose gel electrophoresis.

SYBR green I real-time polymerase chain reactions (RT-PCR) were used to measure the mRNA expression of IGF-I, IGF-II, Pax7, Myf-5, MyoD1, Mstn and $\beta$-actin. First-strand cDNA was synthesized from $5 \mu \mathrm{g}$ of total RNA (processed using DNase) using oligo (dT) primers and Superscript II reverse transcriptase according to the manufacturer's instructions (Tiangen Biotech Co., Ltd, Beijing, China). Real-time PCR was performed in an ABI PRISM 7500 SDS thermal cycler (Applied Biosystems, Foster City, CA). Each sample was analyzed in triplicate. The primers used in the analyses are listed in Table 2. The reactions were performed with $2.0 \mu \mathrm{L}$ of first-strand cDNA and $0.8 \mu \mathrm{L}$ of sense and anti-sense primers in a final volume of $20 \mu \mathrm{L}$ as recommended by the SYBR real-time PCR kit $\left(\mathrm{TaKaRa}^{\circ} \mathrm{BIO}\right.$ CATALOG, Da Lian, China). The RT-PCR conditions were as follows: 1 cycle at $95{ }^{\circ} \mathrm{C}$ for $30 \mathrm{~s}$, and 40 cycles at $95{ }^{\circ} \mathrm{C}$ for $5 \mathrm{~s}$ and $60{ }^{\circ} \mathrm{C}$ for $34 \mathrm{~s}$. The relative expressions of the inflammatory cytokine mRNAs were determined with the $2^{-\Delta \mathrm{Ct}}$ method [24].

Table 2 Primers used for quantitative real-time PCR

\begin{tabular}{|c|c|c|c|}
\hline Gene & $\begin{array}{l}\text { GenBank } \\
\text { Accession } \\
\text { number }\end{array}$ & Primer sequence $\left(5^{\prime} \rightarrow 3^{\prime}\right)^{a}$ & $\begin{array}{l}\text { Amplicon } \\
\text { length, bp }\end{array}$ \\
\hline$\beta$-actin & AY_550069 & $\begin{array}{l}\text { FP: ATGCTTCTAGGCGGACTGT } \\
\text { RP: CCATCCAACCGACTGCT }\end{array}$ & 211 \\
\hline$|G F-|$ & NM_214256 & $\begin{array}{l}\text { FP: CTGTGCTTGCTCTCCTTCAC } \\
\text { RP: TACCCTGTGGGCTTGTTGA }\end{array}$ & 128 \\
\hline$|G F-| \mid$ & NM_213883 & $\begin{array}{l}\text { FP: GTGGCATCGTGGAAGAGTG } \\
\text { RP: GTGGCATCGTGGAAGAGTG }\end{array}$ & 166 \\
\hline Pax7 & XM_005659088 & $\begin{array}{l}\text { FP: CCACATCCGCCACAAGATAG } \\
\text { RP: ATGCCTGGGTTCTCCCTCT }\end{array}$ & 162 \\
\hline Myf-5 & NM_001278775 & $\begin{array}{l}\text { FP: CCAGCCTCTCTCTCTCCAGTT } \\
\text { RP: GCCTCCTTCCTCCTGTGTAATA }\end{array}$ & 151 \\
\hline MyoD1 & NM_001002824 & $\begin{array}{l}\text { FP: AGCGGACGACTTCTATGATGAC } \\
\text { RP: GTGTTCCTCGGGCTITAGG }\end{array}$ & 112 \\
\hline Mstn & NM_001012406 & $\begin{array}{l}\text { FP: TGGTATTTGGCAGAGCATTGAT } \\
\text { RP: CCTGGGAAGGTTACAGCAAGAT }\end{array}$ & 129 \\
\hline
\end{tabular}

${ }^{\mathrm{a}} F P$ forward primer, $R P$ reverse primer

\section{Statistical analyses}

All data were analyzed with SPSS software (SPSS Inc., Chicago, IL, USA) and the results were expressed as LSMEANS, SEM and $P$-values. When treatment differences were detected by ANOVA, the significance of the differences between the treatments was determined with Duncan's multiple range tests. Significance was considered at the probability level of $P<0.05$.

\section{Results}

\section{Growth performance}

The growth performance of offsprings are presented in Table 3. The average daily gain and the average daily feed intake decreased in the corn contaminated with mold group compared with the control group $(P<0.05)$. The gain/feed was also decreased by maternal zearalenone exposure $(P<0.05)$.

The average daily gain raised by adding $1 \%$ MHNTs to maternal diets $(P<0.05)$, but the level did not reach the ADG of control animals. The average daily feed intake also raised following the addition of $1 \%$ MHNTs to the diets $(P<0.05)$.

\section{Muscle fiber diameters and numbers}

The muscle fiber diameters and numbers of offsprings are presented in Table 4. The muscle fiber numbers in the newborn, weaning and growing-finishing pigs were decreased in ZEN-treated group compared with the control group $(P<0.05)$. The moldy corn group exhibited the lower muscle fiber diameters at birth and weaning compared to the control group $(P<0.05)$. There were no differences in the muscle fiber diameters of finishing pigs between the three treatments.

Muscle fiber numbers and diameters at birth, though higher compared to moldy corn group, do not differ significantly when MHNTs were added to maternal diets. Nevertheless, following the addition of MHNTs to maternal diets muscle fiber numbers increased at weaning and slaughter up to control animals levels $(P<0.05)$, and MHNTs reduced the damage in muscle fiber diameters at weaning $(P<0.05)$.

Table 3 Growth performance

\begin{tabular}{llcc}
\hline Item & Control & $2.77 \mathrm{mg} / \mathrm{kg}$ ZEN & $\begin{array}{l}2.76 \mathrm{mg} / \mathrm{kg} \text { ZEN+ } \\
1 \% \mathrm{MHNTs}\end{array}$ \\
\hline ADG, kg/d & $0.68 \pm 0.01^{\mathrm{a}}$ & $0.61 \pm 0.01^{\mathrm{c}}$ & $0.64 \pm 0.01^{\mathrm{b}}$ \\
$\mathrm{ADFl}, \mathrm{kg} / \mathrm{d}$ & $1.88 \pm 0.03^{\mathrm{a}}$ & $1.77 \pm 0.03^{\mathrm{b}}$ & $1.86 \pm 0.03^{\mathrm{a}}$ \\
G:F & $0.36 \pm 0.01^{\mathrm{a}}$ & $0.34 \pm 0.01^{\mathrm{b}}$ & $0.35 \pm 0.01^{\mathrm{ab}}$ \\
\hline
\end{tabular}

Data are means \pm SEM

ZEN zearalenone

MHNTs modified halloysite nanotubes

$A D G$ average daily gain, $A D F I$ average daily feed intake, $G: F$ gain/feed

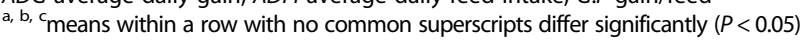


Table 4 Muscle fiber diameters and numbers

\begin{tabular}{|c|c|c|c|}
\hline Item & Control & $2.77 \mathrm{mg} / \mathrm{kg}$ ZEN & $2.76 \mathrm{mg} / \mathrm{kg}$ ZEN+ $1 \%$ MHNTs \\
\hline \multicolumn{4}{|l|}{ Newborn } \\
\hline Muscle fibre numbers & $1.00 \pm 0.02^{b}$ & $0.93 \pm 0.02^{\mathrm{a}}$ & $0.95 \pm 0.02^{\mathrm{ab}}$ \\
\hline Muscle fibre diameter & $9.98 \pm 0.42^{b}$ & $8.40 \pm 0.33^{\mathrm{a}}$ & $9.48 \pm 0.40^{\mathrm{ab}}$ \\
\hline \multicolumn{4}{|l|}{ Weaning } \\
\hline Muscle fibre numbers & $1.00 \pm 0.02^{b}$ & $0.93 \pm 0.03^{\mathrm{a}}$ & $1.01 \pm 0.01^{b}$ \\
\hline Muscle fibre diameter & $18.55 \pm 0.86^{b}$ & $15.40 \pm 0.79^{\mathrm{a}}$ & $18.78 \pm 0.96^{\mathrm{b}}$ \\
\hline \multicolumn{4}{|l|}{ Growing-finishing } \\
\hline Muscle fibre numbers & $1.00 \pm 0.01^{b}$ & $0.97 \pm 0.01^{\mathrm{a}}$ & $1.00 \pm 0.01^{b}$ \\
\hline Muscle fibre diameter & $49.55 \pm 1.63$ & $49.12 \pm 1.04$ & $48.78 \pm 1.64$ \\
\hline
\end{tabular}

Data are means \pm SEM

ZEN zearalenone

MHNTs modified halloysite nanotubes

$\mathrm{a}, \mathrm{b}, \mathrm{c}$ means within a row with no common superscripts differ significantly $(P<0.05)$

The mRNA expression in the longissimus muscle

The mRNA expressions of IGF-I, IGF-II, Pax7, Myf-5, $M y o D 1$ and $M s t n$ in the longissimus muscle are presented in Table 5. The mRNA expression of IGF-I was decreased in the ZEN-contaminated group at birth $(P<0.05)$. No differences in the mRNA expression of IGF-I were observed between the ZEN-contaminated group and the control group at weaning. Maternal zearalenone exposure reduced the expression of IGF-II both at birth and weaning $(P<0.05)$. The results for $M y f-5$ and MyoD1 were similar: the expression of $M y f-5$ was reduced at birth and weaning $(P<0.05)$. The expression of MyoD1 was

Table 5 The mRNA expression in the longissimus muscle

\begin{tabular}{|c|c|c|c|}
\hline Item & Control & $2.77 \mathrm{mg} / \mathrm{kg}$ ZEN & $2.76 \mathrm{mg} / \mathrm{kg}$ ZEN+ $1 \%$ MHNTs \\
\hline \multicolumn{4}{|l|}{ Newborn } \\
\hline$|G F-|$ & $0.0219 \pm 0.0020^{b}$ & $0.0086 \pm 0.0006^{\mathrm{a}}$ & $0.0092 \pm 0.0004^{\mathrm{a}}$ \\
\hline $\mid G F-\|$ & $3.2737 \pm 0.2822^{b}$ & $1.4926 \pm 0.0674^{\mathrm{a}}$ & $3.1937 \pm 0.1827^{b}$ \\
\hline Pax7 & $0.0076 \pm 0.0010$ & $0.0063 \pm 0.0006$ & $0.0059 \pm 0.0007$ \\
\hline Myf-5 & $0.0220 \pm 0.0030^{b}$ & $0.0115 \pm 0.0014^{a}$ & $0.0111 \pm 0.0015^{\mathrm{a}}$ \\
\hline MyoD1 & $0.0176 \pm 0.0020$ & $0.0134 \pm 0.0008$ & $0.0134 \pm 0.0016$ \\
\hline Mstn & $0.0023 \pm 0.0002^{b}$ & $0.0032 \pm 0.0002^{\mathrm{a}}$ & $0.0020 \pm 0.0001^{b}$ \\
\hline \multicolumn{4}{|l|}{ Weaning } \\
\hline$|G F-|$ & $0.0138 \pm 0.0037$ & $0.0094 \pm 0.0011$ & $0.0138 \pm 0.0022$ \\
\hline$|G F-\||$ & $6.8816 \pm 0.4270^{b}$ & $2.4085 \pm 0.1870^{\mathrm{a}}$ & $5.5329 \pm 0.3988^{c}$ \\
\hline Pax7 & $0.0056 \pm 0.0009^{b}$ & $0.0031 \pm 0.0004^{\mathrm{a}}$ & $0.0045 \pm 0.0006^{\mathrm{ab}}$ \\
\hline Myf-5 & $0.0170 \pm 0.0032^{b}$ & $0.0040 \pm 0.0004^{\mathrm{a}}$ & $0.0107 \pm 0.0021^{b}$ \\
\hline MyoD1 & $0.0263 \pm 0.0038^{b}$ & $0.0101 \pm 0.0021^{\mathrm{a}}$ & $0.0152 \pm 0.0045^{\mathrm{a}}$ \\
\hline Mstn & $0.0027 \pm 0.0006$ & $0.0038 \pm 0.0002$ & $0.0029 \pm 0.0002$ \\
\hline \multicolumn{4}{|c|}{ Growing-finishing } \\
\hline$|G F-|$ & $0.1073 \pm 0.0234$ & $0.0899 \pm 0.0160$ & $0.1288 \pm 0.0219$ \\
\hline$|G F-| \mid$ & $6.1416 \pm 0.4666$ & $5.3906 \pm 0.4628$ & $4.8610 \pm 0.5954$ \\
\hline $\operatorname{Pax} 7$ & $0.0232 \pm 0.0042$ & $0.0173 \pm 0.0048$ & $0.0220 \pm 0.0023$ \\
\hline Myf-5 & $0.0212 \pm 0.0011$ & $0.0302 \pm 0.0052$ & $0.0246 \pm 0.0049$ \\
\hline MyoD1 & $0.2534 \pm 0.0184$ & $0.3023 \pm 0.0254$ & $0.2642 \pm 0.0322$ \\
\hline Mstn & $0.0336 \pm 0.0037$ & $0.0341 \pm 0.0032$ & $0.0371 \pm 0.0028$ \\
\hline
\end{tabular}

Data are means \pm SEM

ZEN zearalenone

MHNTs modified halloysite nanotubes

a, b, cmeans within a row with no common superscripts differ significantly $(P<0.05)$ 
also reduced at weaning $(P<0.05)$, but not at birth $(P>0.05)$. The expression of $\operatorname{Pax} 7$ was not affected by zearalenone at birth $(P>0.05)$ but reduced at weaning $(P<0.05)$. Maternal zearalenone exposure increased the expression of Mstn at birth $(P<0.05)$ but not at weaning $(P>0.05)$. However, there were no differences on the mRNA expressions of IGF-I, IGF-II, Pax7, Myf-5, MyoD1 and Mstn in finishing pigs between ZEN-contaminated group and the control.

In this experiment, MHNTs reduced the toxic effects on the expressions of IGF-II and Mstn in newborn piglets $(P<0.05)$, the expressions of IGF-II and Myf-5 $(P<0.05)$ in weaning piglets. The results might show a tendency in reduction of toxic effects on expression of IGF-I,Pax7, $M y o D 1$ in weaning piglets and expressions of IGF-I and Pax7 in growing-finishing pigs, but the mean values obtained do not differ statistically significantly from those obtained for animals fed the ZEN-contaminated diet.

\section{Discussion}

Because the nutritional levels of the three treatments during gestation were similar, and the other experimental conditions were also identical, we hypothesize that the changes in the muscle fibers and mRNA expressions in the offsprings were predominantly caused by maternal ZEN exposure. The ameliorative effects of the treatment with MHNTs were considered to be the result of the addition of this adsorbent to the diet in our study.

The researches on growth performance and muscle development of zearalenone were lacking. Our previous research demonstrated that maternal zearalenone exposure in gestating sows decreased the average body weight at birth and weaning of piglets, and the average daily gain of weaning piglets were also reduced [25]. The previous results were in accord with this experiment. Doll et al. [26] also observed that feed intake and growth rates were reduced in gilts fed diets with deoxynivalenol and zearalenone (DON, $8.6 \mathrm{mg} / \mathrm{kg}$; ZEN, $1.2 \mathrm{mg} / \mathrm{kg}$ ), but the toxin which took effects primarily were undefined. However, some researches had the different conclusions. Zearalenone had no effects on growth performance in prepubertal gilts [27]. Jiang et al. [19] observed gilts fed different amounts of dietary ZEN grew similarly with no differences in ADG and ADFI.

The growth and development of skeletal muscle includes the increases in muscle fiber numbers (hyperplasia) and the enlargements in the volumes of the muscle fibers (hypertrophy). The number of muscle fibers is set a birth, and no further increases occur. The growth and development of muscle consists of only increases in the volumes of muscle fibers; thus, the fetal period plays a key in skeletal muscle development $[28,29]$. In the embryo, a spot of muscle fibers (primary myofibers) begins to develop, and the majority of muscle fibers (secondary myofibers) are formed in the fetal period. The primary myofibers of pigs are formed during the $38 \mathrm{~d}$ of early gestation. The secondary myofibers are formed from 46 to 95 $\mathrm{d}$ of gestation, and muscle fiber numbers do not increase after this period [30, 31]. Skeletal muscle lies at the bottom end of nutrient partitioning during development. As nutrient substances are always first assigned to the nervous system, organs and skeleton, skeletal muscle can easily be affected by maternal nutrition fluctuations [4]. Therefore, such fluctuations can cause irreversible decreases in the numbers of muscle fibers in the fetal period. In the present experiment, maternal ZEN exposure decreased the muscle fiber numbers permanently, muscle fiber diameter were also reduced at birth and weaning compared with the control group. These results accorded with our previous research that the average body weight (BW) of fetuses at $70 \mathrm{~d}$ in pregnant, the litter birth weight, the average $\mathrm{BW}$ of piglet, and the born alive piglet $\mathrm{BW}$ at farrowing were all decreased by ZEN exposure [25]. In contrast to the current study, Kiessling et al. [32] reported that no significant changes in fiber number or diameter occur in male rats after prolonged zearalenone (1.25 or $3.75 \mathrm{mg} / \mathrm{kg}$ ) feeding. ZEN has been found to be maternally toxic and fetotoxic but not teratogenic [33], and it seems that ZEN is unable to affect muscle fibers that have already formed in adult animals. Obviously, the fetuses were affected by maternal toxicity because the sows were fed contaminated diets from 35 to $70 \mathrm{~d}$ of gestation, which is the key period of secondary myofiber development. Differences in the muscle fiber diameters between the three treatments were not observed in the growing-finishing pigs, and these results indicate that the compensation abilities of the offsprings were able to partially eliminate the previous differences.

The process of muscle formation is regulated by series of transcription factors in the embryo that include Wnt, paired boxes (Pax3 and Pax7) and myogenic regulatory factors (MRFs). Pax3 and Pax7 can induce the expression of myogenic regulatory factors and transform myogenous cells to myoblasts [34, 35]. Several myogenic regulatory factors had been found thus far including myogenic differentiation (MyoD), myogenic factor 5 (Myf-5), myogenin and myogenic factor 4 (Myf-4). The actions of MyoD and Myf-5 induce multifunctional myogenous cells to differentiate into myoblasts, and the functions of MyoD and Myf5 seem to be complementary $[34,36]$. In vitro results have indicated that myostatin (Mstn) can directly affect the proliferation or differentiation of many skeletal muscle cell systems and that Mstn can regulate the differentiation of myoblasts by down-regulating the myogenic differentiation factors MyoD, Myf-5 and myogenin [37]. In our experiment, the expression of $\operatorname{Pax} 7, M y f-5$ and $M y o D 1$ were reduced at different periods by maternal ZEN exposure. Meanwhile, the increased expression of MSTN also 
accorded with our results of muscle fiber deterioration. Zhang et al. [25] indicated that placenta weight and the apoptosis-related mRNA expression were altered in the ZEN treatment groups in the placenta and uterus of the sows and piglets. The pathologic uterine and placental changes could affect the functions of the organs and the transportation of nutrition to the fetuses, which may explain the adverse effects on the fetuses [25]. We observed that the expressions of $M y o D$ and $M y f-5$ were increased by ZEN-contaminated treatment at finishing, although these differences were not significant. It is possible that the offsprings in the control group had developed completely, and the slower development of the offsprings in ZEN group had begun to be offset by the compensatory processes. IGFs play critical roles in skeletal muscle differentiation and growth, and previous studies have shown that IGFs not only stimulate myoblast proliferation but also promote myogenic differentiation, which are two mutually exclusive processes [38]. In the present study, the mRNA expression of IGF-I and IGF-II were both decreased in the ZEN-contaminated group at different periods. Previous research has shown that no changes on the expressions of IGF-I or IGF-II was observed by using a diet contaminated with fusarium $(4.42 \mathrm{mg} / \mathrm{kg}$ DON, $0.048 \mathrm{mg} / \mathrm{kg}$ ZEN) from 35 to $70 \mathrm{~d}$ of gestation in neither sows or offsprings compared to a control diet [21]. Oliver et al. [27] observed that zearalenone $(1.5 \mathrm{mg} /$ $\mathrm{kg}$ ) does not alter skeletal muscle signaling in prepubertal gilts. The previous research seems to indicate that zearalenone might affect reproductive performance and thereby affect the development of the offsprings and that ZEN might not induce physiological changes in the muscle fibers or skeletal muscle signaling within a generation. However, our results proved that ZEN has a transgenerational toxicity that affected the muscle development of the offsprings.

With the use of an adsorbent modified with the surfactant SKC, the harmful effects of hydrophobic pesticides from a pollution source can be prevented by clay and soil [39], and the ZEN adsorption efficacies of HNTs and MHNTs have been shown in our previous research [17]. However, the inherent safety of halloysite should also be concerned. The results of Lai et al. [40] indicate that halloysite exhibits a high degree of biocompatibility characterized by an absence of cytotoxicity, in spite of elevated pro-inflammatory cytokine release. Halloysite nanotubes were also found safe for C. elegans at a concentration up to $1 \mathrm{mg} / \mathrm{mL}$ which is about 1,000 times higher than the possible soil contamination concentrations, therefore its quickly growing industrial application is likely to be environmentally safe [41]. In the present experiment, MHNTs alleviated the toxic effects of ZEN on muscle fiber diameters and numbers in piglets. MHNTs also increased the expressions of IGF-I, IGF-II, Pax7, Myf-5 and MyoD1 and reduced the expression of Mstn; these factors are closely related to the physiological changes that occur in muscle fiber. Although the MHNTs did not restore the partial indexes of the offsprings to the normal levels of the control group, an alleviative tendency was observed relative to the ZEN-treated group.

\section{Conclusions}

The present study demonstrated that the offsprings of sows fed with ZEN-contaminated diets from 35 to $70 \mathrm{~d}$ of gestation exhibited weakening on growth performance, physiological changes in their muscle fibers and alterations of mRNA expression in their muscle tissues. Our results also indicated that MHNTs prevented most of the ZEN-induced weakening on growth performance, physiological changes in the muscle fiber and the alterations of mRNA expression in the muscle tissues. MHNTs might be used as effective adsorbents in the feed during the production of sows to alleviate damage to the progeny.

\section{Abbreviations}

ZEN: Zearalenone; MHNTs: Modified halloysite nanotubes; ADG: Average daily gain; ADFI: Average daily feed intake; G:F: gain/feed.

\section{Competing interests}

The authors have declared that they have no competing interests.

\section{Authors' contributions}

AS and YZ conceived and designed the experimental plan. RG and QM performed the experiment, analyzed the data. RG drafted this manuscript, and $M L$ made a revision of this manuscript. $J L$ and $C B$ participated in feeding pigs and collecting samples. All authors read and approved the final manuscript.

\section{Acknowledgments}

This work was supported by National Basic Research Program (2012CB124703), the China Agriculture Research System (CARS-36) and Program for Innovative Research Team of Universities in Heilongjiang Province (2012TD003).

Received: 27 October 2015 Accepted: 17 February 2016

Published online: 29 February 2016

\section{References}

1. Hollinger $\mathrm{K}$, Ekperigin HE. Mycotoxicosis in food producing animals. Vet Clin North Am Food Anim Pract. 1999;15(1):133-65. x.

2. Zinedine A, Soriano JM, Molto JC, Manes J. Review on the toxicity, occurrence, metabolism, detoxification, regulations and intake of zearalenone: an oestrogenic mycotoxin. Food Chem Toxicol. 2007:45(1):1-18.

3. Kollarczik B, Gareis M, Hanelt M. In vitro transformation of the Fusarium mycotoxins deoxynivalenol and zearalenone by the normal gut microflora of pigs. Nat Toxins. 1994;2(3):105-10.

4. Zhu MJ, Ford SP, Means WJ, Hess BW, Nathanielsz PW, Du M. Maternal nutrient restriction affects properties of skeletal muscle in offspring. J Physiol. 2006;575(1):241-50

5. Danicke S, Briissow KP, Goyarts T, Valenta H, Ueberschdr KH, Tiemann U. On the transfer of the Fusarium toxins deoxynivalenol (DON) and zearalenone (ZON) from the sow to the full-term piglet during the last third of gestation. Food Chem Toxicol. 2007:45(9):1565-74. doi:10.1016/fct.2007.02.016.

6. Lvov YM, Shchukin DG, Mohwald H, Price RR. Halloysite clay nanotubes for controlled release of protective agents. ACS Nano. 2008;2(5):814-20.

7. Jinhua W, Xiang Z, Bing Z, Yafei Z, Rui Z, Jindun L, et al. Rapid adsorption of Cr (VI) on modified halloysite nanotubes. Desalination. 2010;259(1):22-8.

8. Shi Y-F, Tian Z, Zhang Y, Shen H-B, Jia N-Q. Functionalized halloysite nanotube-based carrier for intracellular delivery of antisense oligonucleotides. Nanoscale Res Lett. 2011;6(1):1-7. 
9. Qi R, Guo R, Shen M, Cao X, Zhang L, Xu J, et al. Electrospun poly (lactic-coglycolic acid)/halloysite nanotube composite nanofibers for drug encapsulation and sustained release. J Mater Chem. 2010;20(47):10622-9.

10. Etienne $M$, Jemmali $M$. Effects of zearalenone (F2) on estrous activity and reproduction in gilts. J Anim Sci. 1982;55(1):1-10.

11. Zhang Y, Jia Z, Yin S, Shan A, Gao R, Qu Z, et al. Toxic effects of maternal zearalenone exposure on uterine capacity and fetal development in gestation rats. Reprod Sci. 2013. doi:10.1177/1933719113512533.

12. Becci PJ, Johnson WD, Hess FG, Gallo MA, Parent RA, Taylor JM. Combined two-generation reproduction-teratogenesis study of zearalenone in the rat. J Appl Toxicol. 1982;2(4):201-6. doi:10.1002/jat.2550020406.

13. Schoevers EJ, Santos RR, Colenbrander B, Fink-Gremmels J, Roelen BA. Transgenerational toxicity of Zearalenone in pigs. Reprod Toxicol. 2012;34(1):110-9.

14. Lígia Martins M, Marina Martins $\mathrm{H}$. Influence of water activity, temperature and incubation time on the simultaneous production of deoxynivalenol and zearalenone in corn (Zea mays) by Fusarium graminearum. Food Chem. 2002;79(3):315-8.

15. Demyttenaere JC, Moriña RM, De Kimpe N, Sandra P. Use of headspace solid-phase microextraction and headspace sorptive extraction for the detection of the volatile metabolites produced by toxigenic (Fusarium) species. J Chromatogr. 2004;1027(1):147-54.

16. Queiroz VAV, de Oliveira Alves GL, da Conceição RRP, Guimarães LJM, Mendes SM, de Aquino Ribeiro PE, et al. Occurrence of fumonisins and zearalenone in maize stored in family farm in Minas Gerais, Brazil. Food Control. 2012;28(1):83-6.

17. Zhang Y, Gao R, Liu M, Yan C, Shan A. Adsorption of modified halloysite nanotubes in vitro and the protective effect in rats exposed to zearalenone. Arch Anim Nutr. 2014;68(4):320-35.

18. Lemke SL, Mayura K, Reeves WR, Wang N, Fickey C, Phillips TD. Investigation of organophilic montmorillonite clay inclusion in zearalenone-contaminated diets using the mouse uterine weight bioassay. J Toxicol Environ Health A. 2001;62(4):243-58.

19. Jiang S, Yang Z, Yang W, Yao B, Zhao H, Liu F, et al. Effects of feeding purified zearalenone contaminated diets with or without clay enterosorbent on growth, nutrient availability, and genital organs in post-weaning female pigs. Asian-Aust J Anim Sci. 2010;23(1):74-81.

20. Jiang $S$, Yang Z, Yang W, Wang S, Liu F, Johnston L, et al. Effect of purified zearalenone with or without modified montmorillonite on nutrient availability, genital organs and serum hormones in post-weaning piglets. Livest Sci. 2012;144(1):110-8.

21. Tiemann U, Brüssow K-P, Dänicke $S$, Vanselow J. Feeding of pregnant sows with mycotoxin-contaminated diets and their non-effect on foetal and maternal hepatic transcription of genes of the insulin-like growth factor system. Food Addit Contam. 2008;25(11):1365-73.

22. NRC. Nutrient requirements of swine. Washington, DC: National Academic Press; 2012.

23. Greenwood PL, Slepetis RM, Bell AW, Hermanson JW. Intrauterine growth retardation is associated with reduced cell cycle activity, but not myofibre number, in ovine fetal muscle. Reprod Fertil Dev. 1999;11(5):281-91.

24. Bousquet L, Pruvost A, Guyot AC, Farinotti R, Mabondzo A. Combination of Tenofovir and emtricitabine plus Efavirenz: in vitro modulation of $A B C$ transporter and intracellular drug accumulation. Antimicrob Agents Chemother. 2009;53(3):896-902. doi:10.1128/aac.00733-08.

25. Zhang Y, Gao R, Liu M, Shi B, Shan A, Cheng B. Use of modified halloysite nanotubes in the feed reduces the toxic effects of zearalenone on sow reproduction and piglet development. Theriogenology. 2014;83(5):932-41.

26. Doll S, Danicke S, Ueberschar KH, Valenta H, Schnurrbusch U, Ganter M, et al. Effects of graded levels of Fusarium toxin contaminated maize in diets for female weaned piglets. Arch Anim Nutr-Arch Tierernahr. 2003;57(5):311-34 doi:10.1080/00039420310001607680.

27. Oliver W, Miles J, Diaz D, Dibner J, Rottinghaus G, Harrell R. Zearalenone enhances reproductive tract development, but does not alter skeletal muscle signaling in prepubertal gilts. Anim Feed Sci Technol. 2012;174(1):79-85.

28. Stickland N. A quantitative study of muscle development in the bovine foetus (Bos indicus). Anat Histol Embryol. 1978;7(3):193-205.

29. Du M, Zhu M. Fetal programming of skeletal muscle development. Appl Musc Biol Meat Sci. 2009:81-96

30. Wigmore P, Stickland N. Muscle development in large and small pig fetuses. J Anat. 1983;137(Pt 2):235.
31. Handel S, Stickland N. The effects of low birthweight on the ultrastructural development of two myofibre types in the pig. J Anat. 1987;150:129.

32. Kiessling $\mathrm{KH}$. The effect of zearalenone on growth rate, organ weight and muscle fibre composition in growing rats. Acta Pharmacol Toxicol. 1982;51(2):154-8.

33. Collins TF, Sprando RL, Black TN, Olejnik N, Eppley RM, Alam HZ, et al. Effects of zearalenone on in utero development in rats. Food Chem Toxicol. 2006;44(9):1455-65.

34. Maroto $M$, Reshef $R$, Münsterberg $A E$, Koester $S$, Goulding M, Lassar AB. Ectopic Pax-3 activates MyoD and Myf-5 expression in embryonic mesoderm and neural tissue. Cell. 1997;89(1):139-48.

35. Hyatt JPK, McCall GE, Kander EM, Zhong H, Roy RR, Huey KA. PAX3/7 expression coincides with MyoD during chronic skeletal muscle overload. Muscle Nerve. 2008;38(1):861-6.

36. Roth JF, Shikama N, Henzen C, Desbaillets I, Lutz W, Marino S, et al. Differential role of p300 and CBP acetyltransferase during myogenesis: p300 acts upstream of MyoD and Myf5. EMBO J. 2003;22(19):5186-96.

37. Ríos R, Carneiro I, Arce VM, Devesa J. Myostatin is an inhibitor of myogenic differentiation. Am J Physiol-Cell Physiol. 2002;282(5):C993-C9.

38. Duan C, Ren H, Gao S. Insulin-like growth factors (IGFs), IGF receptors, and IGF-binding proteins: roles in skeletal muscle growth and differentiation. Gen Comp Endocrinol. 2010;167(3):344-51.

39. Sanchez-Martin M, Rodriguez-Cruz M, Andrades M, Sanchez-Camazano M. Efficiency of different clay minerals modified with a cationic surfactant in the adsorption of pesticides: influence of clay type and pesticide hydrophobicity. Appl Clay Sci. 2006:31(3):216-28.

40. Lai X, Agarwal M, Lvov YM, Pachpande C, Varahramyan K, Witzmann FA. Proteomic profiling of halloysite clay nanotube exposure in intestinal cell co-culture. J Appl Toxicol. 2013;33(11):1316-29.

41. Fakhrullina Gl, Akhatova FS, Lvov YM, Fakhrullin RF. Toxicity of halloysite clay nanotubes in vivo: a Caenorhabditis elegans study. Environ Sci: Nano. 2015;2(1):54-9.

42. Xiong B, Pang Z, Luo Q. Tables of feed composition and nutritive values in China. Chin Feed. 2008;22:35-35.

\section{Submit your next manuscript to BioMed Central and we will help you at every step:}

- We accept pre-submission inquiries

- Our selector tool helps you to find the most relevant journal

- We provide round the clock customer support

- Convenient online submission

- Thorough peer review

- Inclusion in PubMed and all major indexing services

- Maximum visibility for your research

Submit your manuscript at www.biomedcentral.com/submit
Biomed Central 